\title{
Vínculos parentales y afectivos de familias migrantes del Caribe colombiano a Venezuela
}

\author{
Gloria Bonilla Vélez ${ }^{(\star)}$
}

\section{Resumen}

Este artículo pretende hacer un aporte al análisis de la emigración contemporánea de madres y padres de la Costa Caribe Colombiana, a partir de datos históricos y fuentes orales recurriendo a relatos de familiares e hijos/as que quedan en las ciudades de origen. Responde a la necesidad de comprender los efectos de esa migración tanto en los países de destino como en los de origen desde la perspectiva de quienes se quedan.

Palabras claves: migraciones, Colombia, Venezuela, siglo XX

\section{Abstract}

This article aims to contribute to an analysis of contemporary migration of parents from the Caribbean Coast of Colombia, from historical data and using oral history accounts of family and children/as remaining in the home cities. Responds to the need to understand the effects of migration both in countries of destination and the source from the perspective of the who remain.

Key words: migration, Colombia, Venezuela, the twentieth century.

\footnotetext{
(*) Profesora Titular Programa de Historia. Facultad de Ciencias Humanas. Universidad de Cartagena. Grupo de investigaciones Frontera, Sociedad y Cultura en el Caribe y Latinoamérica.

- Recibido: Junio de 2011 - Aprobado: Noviembre de 2011 


\section{Introducción}

${ }^{1}$ estudio de las migraciones desde una perspectiva tranasnacional Eproporciona un nuevo marco analítico que hace visible la creciente intensidad de los flujos poliédricos de personas, objetos, información y símbolos y permite analizar como los migrantes construyen y reconstruyen sus vidas simultáneamente imbricadas en más de una sociedad. Abordar las migraciones internacionales desde la perspectiva trasnacional requiere superar el "nacionalismo metodológico", a saber la asunción de que el Estado-nación s el contenedor natural y lógico dentro del cual transcurre la vida social.

Por esta razón, y a fin de obtener un campo de observación a la vez trasnacional y longitudinal -en nuestro estudio- hemos optado por la metodología de carácter cualitativo. La investigación se hizo en el espacio urbano de Cartagena y Barranquilla, principalmente en los lugares que albergan una significativa cantidad de hogares marcados o generados por la emigración a Venezuela. A través de la entrevista a profundidad como técnica de recogida de datos, nos acercamos, por un lado a los familiares (hijos, hijas, cuidadores, cuidadoras residentes en estas ciudades y que tienen sus parientes emigrados a Venezuela y por otro, a los emigrantes de referencia residentes en distintas ciudades de Venezuela pertenecientes a las mismas familias. ${ }^{1}$

La frontera compartida por Colombia y Venezuela ha sido escenario de una gran actividad económica y social durante siglos. Las migraciones que han conectado algunas comunidades rurales en ambos países han contribuido a la formación de una de las zonas fronterizas mas activas de América Latina. Estas relaciones están basadas en lazos de amistad, familiares y en múltiples vínculos económicos, unidos a una herencia histórica y cultural común. Hoy en día, los inmigrantes colombianos conforman la mayor parte de la población inmigrante a Venezuela, y una porción significativa de ellos, surten constantemente los requerimientos de mano de obra agrícola de los Andes venezolanos. ${ }^{2}$

En la región fronteriza de Colombia y Venezuela h funcionado durante al menos los últimos cuatro siglos un sistema de interacción regional estructurado a partir de los intercambios comerciales y de flujos poblacionales. De hecho, desde la formación de ambas republicas (1830) en numerosas ocasiones la frontera internacional no ha constituido más que un obstáculo al desarrollo económico

\footnotetext{
1 Este articulo hace parte de una investigación mas amplia financiada por Colciencias y la Vicerrectoria de Investigaciones de la Universidad de Cartagena Cambios y conflictos de las familias frente a la migración internacional. Fue realizada por cinco universidades: Universidad de Antioquia, Universidad de Caldas, Universidad del Valle, Universidad Nacional y Universidad de Cartagena.

2 Susan Berglund y Humberto Hernández, Los de afuera: Un estudio analítico del proceso migratorio a Venezuela 1936-1985, Caracas, CEPAM, 1986, p. 45; Chen, Chi Y, Inserción laboral y migración colombiana a Venezuela, Caracas, Instituto de Investigaciones Sociales y Económicas, 1989; Luz Marina Díaz y Alcides Gómez, "Fuerza de trabajo y mercado laboral de los migrantes colombianos a Venezuela", en Las migraciones de colombianos a Venezuela, UCAB, Caracas, 1987.
} 
de sus regiones fronterizas. Y desde entonces, esas relaciones han pasado por numerosos vaivenes ligados a diferentes periodos en la orientación económica y política de ambos países. ${ }^{3}$

La migración internacional de colombianos/as en las últimas décadas del siglo XX y los primeros años del XXI, ha despertado el interés en las investigaciones sociales desde la antropología, la sociología, la historia, la ciencia política, la economía y el trabajo social. Hoy se cuenta con una riqueza y abundancia de trabajos que ha indagado sobre el origen y las causas que motivaron este fenómeno, sobre los cambios y patrones de migración respecto a flujos anteriores, acerca de la inserción laboral y social de las poblaciones migrantes especialmente en los países de destino. Desde 1970 hay un flujo migratorio muy importante de mujeres a Venezuela. Según el estudio de Gabriel Murillo el caso de Venezuela llama la atención porque se trata de una "emigración de los estratos bajo populares de ciudades como Cúcuta, Cartagena, Barranquilla y Bucaramanga y Riohacha”. ${ }^{4}$ Las edades tanto de hombre como de mujeres emigrantes a Venezuela desde Colombia en su mayoría son jóvenes de menos de 30 años y este desplazamiento afecta significativamente la composición familiar y la distribución espacial en el país. "Esta población tanto femenina como masculina que migra en edad fértil altera el ritmo de las tasas de crecimiento poblacional dado que al estar ausentes de sus hogares disminuyen las posibilidades de reproducción poblacional, pero igualmente causa un efecto parecido en el país de destino dado que la llegada de este componente poblacional, al entablar nuevas relaciones temporales o estables con la población nativa de Venezuela también altera la composición familiar y las tasas de crecimiento y de reproducción laboral". 5

La emigración colombiana de fines de los ochentas y noventas marca cambios importantes en la tradición migratoria del país y sus consecuencias son muy grandes, no sólo en la economía, sino además, en las relaciones transnacionales que se sostienen entre quienes emigran y los que se quedan con sus consecuentes cambios en las dinámicas familiares, por lo cual hoy es un tema de interés académico en las distintas regiones del país que están aportando la mayor parte de la población migrante desde territorio colombiano.

La necesidad de contribuir con estudios que ayuden a comprender el fenómeno migratorio desde la región Caribe, la situación de nuestros connacionales en los países de destino, es apremiante, pero sus resultados deben ir más allá de

\footnotetext{
Margarita Jiménez y Sandro Sideri. Bogota, Fondo Editorial CEREC, 1985. Luis Llambi, "The Venezuela-Colombia Borderlands: a regional and historical perspectiva". En Jornal of Borderlands Studies, IV, (1): 1-38. 1989. German Freire, "Migraciones rurales. Un estudio a ambos lados de la frontera Colombo-venezolana", en Boletín Antropológico Mérida, Universidad de los Andes, 2004

4 Gabriel Murillo, La emigración laboral de colombianos a Venezuela, Bogota, PNUD, Ministerio de Trabajo, 1979.

5 Alcides Gómez y Julio Mora, Flujos migratorios de las zonas de frontera colombiana a Venezuela, Caracas, Universidad de Maracaibo/Universidad Central de Venezuela/Centro de Investigaciones Demográficas, 1972. Alcides Gómez, Dinámica de las migraciones colombianas a Venezuela, Bogota, Universidad Nacional/ Tercer Mundo, 1999.
} 
la compresión del fenómeno, en la medida que también deben aportar hacia la construcción de políticas migratorias en materia de derechos y oportunidades reales para las familias que no encuentran en nuestras ciudades una respuesta frente a sus demandas.

Este articulo pretende hacer un aporte al análisis de la emigración contemporánea de madres y padres de la costa Caribe colombiana, a partir de datos históricos y fuentes orales recurriendo a los relatos de familiares e hijos/as que quedan en las ciudades de origen, específicamente en las ciudades de Cartagena, Arjona, Maria La Baja, Mahates, Maicao, Riohacha y Barranquilla, producto de una investigación en desarrollo a nivel nacional. ${ }^{6}$

Este artículo responde a la necesidad de comprender los efectos de esa migración tanto en los países de destino como en los de origen ${ }^{7}$ desde la perspectiva de quienes se quedan. Los procesos migratorios históricamente han estado motivados por factores económicos y laborales para atender necesidades de subsistencia, mejores ingresos y/o proteger la vida cuando esta es amenazada por la agudización de la inseguridad y las persecuciones políticas entre los distintos actores del conflicto armado en nuestro país. Sin embargo, hoy desde los procesos de globalización se ha marcado e incrementado la diversificación de los flujos migratorios en cuanto a quienes migran y los destinos elegidos por los colombianos/as en busca de nuevos horizontes.

Son pocos los estudios que además de analizar los flujos y las olas migratorias hacia Venezuela, se interesan por comprender porque las familias continúan sosteniendo esta tradición histórica pese a los cambios económicos, políticos y sociales que este país viene presentando y sus consecuentes repercusiones en sus políticas migratorias. Intentaremos provocar una reflexión y nuevas preguntas alrededor de este tema.

\section{Aspectos históricos de la emigración de colombianos/as hacia Venezuela}

La revisión de estudios como el de Raquel Álvarez, sobre la evolución histórica de la migración a Venezuela permite identificar que desde 1950, este país ha funcionado como receptor de mano de obra colombiana calificada, no calificada y campesina, principalmente en zonas fronterizas, por las relaciones de vecindad,

\footnotetext{
$6 \quad$ Quiero agradecer el apoyo a los estudiantes Felipe Izquierdo y Sandra Prasca quienes adelantan sus monografías de grado en la línea de Migración, Genero y Familia.

7 Alba Goicoechea y Franklin Ramírez, Los hijos de la Migración. Impactos sociales en la familia, Quito, Universidad Simón Bolívar, 2008; Isabel Yepes y Gioconda Herrera, Nuevas Migraciones Latinoamericanas a Europa. Balances y Desafíos, Quito, FLACSO, 2009; Wagner Keike, "Migrantes Ecuatorianos en Madrid. Reconstruyendo Identidades de Genero", en. Ecuador Debate No. 63, Quito, 2004. Jason Pribilsky, "Los hijos de las remesas, y traumas de la globalización", en Ecuador Debate No. 54, Quito, 2000. Ana Luz Borrero, "Migración Latinoamericana a España", en Revista Migraciones, Barcelona, 2001. Agrela Belén, "Ser Madres en familias trasnacionales", en V Congreso Migraciones, Asociación de Emigrantes, Bilbao, 2002; Pablo Villafañe, Migración a de colombianos al Táchira 1903-1983, San Cristóbal, Biblioteca de Autores Tachirenses, 1983.
} 
permeabilidad de las fronteras y facilidades comunicacionales que actúan como factores a favor de esta migración. ${ }^{8}$

Según los censos de población de Venezuela, el número de colombianos residenciados entre los años 1951 y 1971 tuvo una variación significativa, pasando de 45.969 a 102.314. Estas corrientes migratorias provenían básicamente del otro lado de la frontera, siendo los habitantes de la Costa Atlántica y Antioquia quienes se dirigían hacia el estado de Zulia. Mientras los residentes en los departamentos de la región andina, se trasladaron hacia el Táchira, Barinas, entre otros estados. Caracas siempre fue considerada como uno de los grandes polos de atracción para los migrantes colombianos, ${ }^{9}$ al igual que las principales ciudades del país: Maracaibo, Barquisimeto, Valencia, San Cristóbal. ${ }^{10}$

Los estudios realizados sobre la población migrante en la época de la explosión demográfica clandestina (1974-1982) hacia Venezuela, Dávila reafirma la relativa facilidad con la que lograban ubicarse laboralmente los colombianos, con el apoyo de amigos o familiares establecidos legal o clandestinamente,$^{11}$ lo cual evidencia la importancia histórica de su atractivo económico y de las redes familiares y sociales que han sostenido un mercado laboral transfronterizo.

De la información contenida en algunos estudios sobre deportaciones, realizados en la época de la explosión demográfica clandestina que cita este mismo autor, fue posible identificar algunas características de esta inmigración de colombianos/ as. En primer lugar muestran una migración mayoritariamente masculina, las mujeres migrantes alcanzaban un $20 \%$ de esta población indocumentada, por otra parte, migraban en edad productiva, y con bajos niveles de escolaridad, con la particularidad que viajaban solos y tenían a sus familiares en Colombia. Los motivos más frecuentes por los cuales migraban eran el desempleo y la búsqueda de mejores salarios, con una mayor tendencia a ubicarse en el sector informal de la economía como una forma de evadir los controles oficiales. ${ }^{12}$

Otros estudios muestran además que el patrón distintivo de la migración dentro de la subregión andina refleja que el flujo de colombianos hacia Venezuela es el de

\footnotetext{
8 Raquel Álvarez, "La dinámica migratoria colombo-venezolana: Evolución y perspectiva actual”, en Geoenseñanza, vol 9, No. 2, Mérida, Universidad de los Andes, 2004, pp. 191, 194.

9 Raquel Álvarez, "Evolución histórica de las migraciones a Venezuela. Breve recuento", en Aldea Mundo, San Cristóbal Venezuela, Universidad de los Andes, 2006.

10 Diversos estudios mostraban que en la época de la inmigración clandestina en estas ciudades por cada restaurante había como mínimo un colombiano indocumentado; que de cada diez personas, ocho eran colombianos indocumentados" (Cardona, 1985: 235), y que en casi todas las casas de familias ricas y de clase media trabajaban uno o dos ilegales, Ricardo Dávila, "Fronteras Confusas. Impactos sociales de la migración" En Revista Virtual de Estudios Literarios y Culturales Centroamericanos, Itsmo. Universidad de los Andes, Venezuela, 2002, disponible en: collaborations. denison.edu/istmo/.../fronteras.html.consultada en diciembre, 2009.

${ }_{11}$ Ricardo Dávila, "Migración indocumentada a Venezuela”, Memorias Congreso Migraciones, Trabajo y Crisis Económica en América Latina, Universidad de Costa Rica, 2000.

12 Luz Marina Díaz y Alcides Gómez. La Moderna esclavitud los indocumentados colombianos a Venezuela, Bogota, Editorial Oveja Negra, 1983, pp 36 y ss.
} 
mayor cuantía y visibilidad entre los intercambios migratorios. Los colombianos en Venezuela representaban el $76 \%$ del total de migrantes intracomunitarios hacia 1990. Esta nación aglutina al 84\% de los inmigrantes y Colombia aporta el $82 \%$ de los emigrantes andinos. ${ }^{13}$

\section{La emigración desde la región Caribe a Venezuela}

La migración internacional de población desde lo que hoy conocemos como el Caribe Colombiano, según referencias más tempranas la sitúan en los años cincuenta, pero la emigración masiva tiene su origen a fines de los ochentas. ${ }^{14}$ Esta emigración es particularmente importante no solo a nivel de las familias y comunidades con dicha experiencia, sino a nivel nacional, por la gran cantidad de población movilizada. Este proceso migratorio tiene algunas características particulares respecto a la emigración tradicional en el país que conviene resaltar.

En primer lugar, la emigración es masiva, y, como tal, ocurre a partir de la crisis económica de la región Caribe a fines de los sesentas. Sólo en el año 1972, salieron alrededor de medio millón de personas, y el saldo entre las que entraron y salieron, favorables a las salidas, equivalió al 3\% de las migraciones trasnacionales de los años 70. En el periodo de 1960 a 1973 llega a Venezuela una significativa corriente migratoria de colombianos atraídos por las oportunidades generadas por el petróleo ante la imposibilidad de acceder a mayores ingresos que en su país de origen. ${ }^{15}$

En segundo lugar, los patrones de procedencia y destino de la migración han cambiado. El ritmo de la emigración, aunque no necesariamente su magnitud relativa, fue de mayoría procedente del sector rural, que han sido los tradicionalmente emigrantes, lo cual está correlacionado con el mayor crecimiento de la pobreza y el desempleo en esa región y sector. En cuanto al destino de la emigración, el gran cambio ha sido el mayor traslado hacia países europeos, principalmente España, en lugar de Estados Unidos, destino habitual de los emigrantes colombianos hasta $1995 .{ }^{16} \mathrm{Y}$ en cuanto a los estratos sociales se ha confirmado que la migración a países como Venezuela es de los sectores de

\footnotetext{
13 Documento CEPAL-CELADE-OIM. Proyecto SIMICA. Por otra parte, a nivel interno las regiones de mayor flujo migratorio hacia este país han sido la región oriental y la Costa Atlántica de Colombia.

14 Raquel. Ảlvarez, Evolución Histórica de Emigrantes a Venezuela. Ministerio de Relaciones Exteriores de Venezuela, Caracas, 2007.

15 Ricardo, Torralba, Las migraciones de colombianos a Venezuela. Universidad de los Andes, Caracas, 1987. Ana María. Bidegain, Las migraciones laborales de colombianos a Venezuela. Caracas, Instituto Latinoamericano de Investigaciones Sociales, 1987. Ana Maria Bidegain, y Antonio Frietz. Colombianos a Venezuela: mito y realidad. Caracas, Centro de Estudios de la Pastoral Social y Asistencia Migratoria. 1989

16 La reciente Encuesta Nacional sobre migraciones internacionales y Remesas, presenta los destinos elegidos por los colombianos donde España ocupa el primer lugar (38,5\%), Estados Unidos (25,8\%) el segundo y Venezuela (16,5\%) es el tercer país, que aun sostiene un importante flujo migratorio. En Encuesta Nacional 2008-2009. Resultados generales de Migraciones Internacionales y Remesas. Observatorio Distrital de Migraciones. Bogotá D.C. Observatorio Colombiano de Migraciones. Fundación Esperanza-Red Alma Mater. P. 33. 2009.
} 
condición económica más pobre, ${ }^{17}$ pues para viajar al Zulia, Caracas o Maracaibo no se requieren altos costos como puede implicar un billete de avión a Miami, New York, Madrid, Bilbao o Barcelona. Así lo expresan unos relatos de la región al relatar por que eligen a Venezuela.

Ella se fue, primero, porque las condiciones monetarias, su anhelo era irse para Estados Unidos, pero en ese entonces los medios no le alcanzaban para que ella se fuera a Estados Unidos, y decidió irse para Caracas. Tía Cuidadora. Barranquilla.

Porque en Venezuela como en todos los tiempos hasta ahora, es el país más cerca de Colombia es el que todos ven más fácil el ingreso y es el que las personas piensan que hay como mejores trabajos y mejor agilidad para mandar dinero para que las personas sigan subsistiendo de ellos. Hijo. Cartagena.

Porque en Venezuela tiene a la hermana, y Venezuela yo creo que es el país donde uno más fácil puede entrar. Madre Cuidadora. Barranquilla.

Mi mama se fue a Venezuela pues allí vivía la abuela desde hace 30 años, en Caracas nacieron sus nueve hijos, tenía la nacionalidad, casa, trabajo, fue muy fácil irse, y rápido consiguió trabajo en una casa de una familia venezolana de mucho dinero, además le pagaban y la trataban muy bien. Hija Maicao.

En tercer lugar, es preciso advertir que la migración femenina a Venezuela ha sido una constante. Esto tienen que ver con varios factores como la existencia de una demanda internacional de trabajadoras del ámbito doméstico con unos mejores salarios que en la región Caribe, ayer en Venezuela hoy a España; procesos de reunificación familiar, para el caso de la migración más antigua; y, finalmente, la mayor disposición de las familias a asumir riesgos, que van de la mano con nuevos roles de las mujeres, debido, en parte, a los mismos efectos de la migración precedente.

En Cartagena, se sigue identificado un importante flujo migratorio hacia Venezuela, reflejado en los datos del último Censo (DANE), ${ }^{18}$ situación también encontrada en Barranquilla. Los relatos revelan que quienes migran a Venezuela se afirma que es debido a la situación de pobreza de las familias de los sectores populares, identificada como uno de los motivos más importantes para que padres y/o madres tengan que migrar en busca de mejores oportunidades. Esta

DANE, ENH, 2005.

18 El Censo que realizó durante el año 2005 el Departamento Administrativo Nacional de Estadística (DANE) reveló que un porcentaje importante de Cartageneros tienen algún tipo de experiencia migratoria, ya sea porque un familiar vive en el exterior o porque ellos mismos han viajado. Las diferencias encontradas están relacionadas con sus condiciones socio-económicas de acuerdo a la estratificación social de la ciudad. En los estratos más altos, el censo reveló que el 6,6 \% de las familias tiene algún familiar viviendo en el exterior, mientras en los estratos más bajos este porcentaje llega al $0,9 \%$. En los países de destino también se encontraron diferencias. Los estratos altos emigran hacia Estados Unidos $(61,9 \%)$, España (el $8,7 \%)$ y Canadá $(5,7 \%)$. Mientras los estratos bajos tienen como principal destino a Venezuela (88,3\%), seguido por Panamá (4,5\%) y en último lugar está Estados Unidos con el 2,8\%. 
situación podría estar relacionada con el contexto económico de Cartagena y Barranquilla que en los últimos diez años ha estado afectada por el creciente desempleo, el subempleo reflejado en la informalidad, la inestabilidad laboral y los ingresos bajos e insuficientes para cubrir las necesidades básicas de los hogares. Así lo relatan algunos familiares entrevistados:

El trabajaba donde le saliera, así que si de pronto lo necesitaban un día pa de ayudante, que pa albañilería, el se iba, pero trabajo fijo, fijo, no tenia. (Hijo Cartagena). Mi mamá era la que trabajaba aquí, pero la plata no le alcanzaba, porque lo que se ganaba era el mínimo. (Hija Cartagena).

Mi mamá se fue por la falta de empleo, aquí no encontraba trabajo, por eso la ayudó mi tío que ya estaba en Venezuela. (Hija. Cartagena). Aquí uno trabaja y trabaja, y las cosas no las ve productivas, la plata no le alcanza y uno ve personas que emigran, y a los dos o tres años logran cosas que acá a pesar de todo el tiempo que estuvieron trabajando, no las pudieron lograr; en esa parte, si persiste que las personas emigren hacia Venezuela. (Prima cuidadora Barranquilla). Mi papá tomó la decisión de irse hacia Caracas porque tenía como un año que no conseguía trabajo y nosotros somos tres hijos y es el que corre con todos los gastos de nosotros. (Hijo Barranquilla).

\section{Las redes familiares y las cadenas migratorias hacia Venezuela}

En el contexto de la migración internacional las redes se entienden como un "conjunto de vínculos interpersonales que conectan a migrantes, antiguos migrantes y no migrantes en su área de origen y de destino a través de los lazos de parentesco, amistad y comunidad de origen compartida". ${ }^{19}$ La decisión de emigrar no ocurre en términos de opciones personales realizadas de forma individual y aislada por cada emigrante. Por el contrario, tanto la toma de decisiones como el abastecimiento de los recursos necesarios se produce en el contexto del grupo familiar nuclear, ampliado o extenso. ${ }^{20}$ Los estudios revisados también dan cuenta que desde los años setenta y ochenta, se identificó la existencia de redes familiares que sostenían el flujo migratorio entre los dos países que ayudaban a ubicarlos laboralmente y a mantenerse en Venezuela hasta que lograran la reunificación familiar. ${ }^{21}$

19 Douglas, Massey, Arango, et.al. Teorías sobre migración internacional. Una reseña y aproximación. En: Population and Development Review, 19, No. 3. Septiembre. Traducido del inglés por Augusto Aguilar Calahorro. Publicado en: ReDCE, No. 10-Diciembre, 2008. Joaquín, Arango, (2000) Enfoques conceptuales y teóricos para explicar la migración” en Revista Internacional de Ciencias Sociales No. 165. UNESCO.

20 Se ha encontrado diversidad de formas familiares en los hogares de origen de los migrantes en Cartagena y Barranquilla, como los hogares monoparentales por separación de la pareja, u hogares conformados por hijos ante la migración de padre y madre, con un apoyo importante de la familia extensa en la mayoría de los casos.

21 La numerosa comunidad colombiana establecida legalmente (227.000 personas para mediados de 1979) operaba, al mismo tiempo, como un factor de atracción de inmigrantes al país bajo la modalidad 
Tengo nueve hermanas en Venezuela. Una hermana desde joven se fue, después mandaron a buscara a la otra, y así, total que todas se fueron, las últimas y las mayores están allá, porque tengo una hermana que está pensionada allá. Porque mis hermanas venían y me veían pasando trabajo y yo no tenía donde vivir y ellas me decían mi hermanita, vamos que con lo que tú te ganes en cinco años compras tu casa, porque ya todas tienen casa y así yo lo hice, yo cerré los ojos dejé a mis hijos con mi suegra y me fui y trabaje cinco años con una familia. Y yo mandé a mi hija para allá, y lleva diez años también en casa de familia, se fue a trabajar para ayudar a levantar a sus hijos". Abuela cuidadora. Cartagena. 61 años.

Hay varios parientes que viven allá, hay una tía que es la que le sigue a mi mamá; que ya tiene cuarenta años de estar allá. Ella fue la primera que se fue; y a partir de ahí ya todos se fueron yendo, como te digo; ellas son seis con mi mamá, y prácticamente allá se han hecho cuatro, una que está aquí y es pensionada ya; y otra que sale pensionada este año en Venezuela. Hija Barranquilla.

Mi abuela fue la primera que se fue a Venezuela, ella vivió cuarenta años se regreso hace ocho años poco a poco se fue, llevando los hijos, y hoy en día viven allá siete hijos de los diez que tiene, en Caracas y Maracaibo viven varios hermanos de mi abuela que son ya de allá prácticamente. Hija Cartagena.

Los relatos anteriores permiten identificar no solo las redes familiares que sostienen la migración entre los dos países, sino la cadenas migratorias y de cuidado que se reproducen intergeneracionalmente, teniendo en cuenta que el trabajo doméstico es una de las mayores ofertas laborales para las madres migrante ${ }^{22}$ como actividades adsdcritas culturalmente a las mujeres, observando que se siguen reproduciendo en los países de destino y que en este caso, se viene constituyendo en una oportunidad para acceder a una vivienda, a una pensión, que no veían posible en Cartagena o Barranquilla, convirtiéndose en un factor atractivo para otras migrantes potenciales.

La emigración colombiana contemporánea tiene mucho que ver con una estrategia económica familiar y, en este sentido, no difiere mucho del comportamiento de la migración interna, la diferencia está en la escala de la movilidad, tanto espacial como económica. Por un lado, la emigración compromete a más de un

de "reunificación familiar". Adicionalmente, se hizo evidente un flujo turístico de familiares, parientes y amigos de migrantes ya legalizados, sobre todo colombianos, dadas las facilidades de acceso por la condición de países vecinos, de los cuales un alto porcentaje entraban con la finalidad de residir entre el resto de la población colombiana con residencia y empleo ilegales en Venezuela (Revista Migrantes, vol. XXV, No 309, 7.10.1979, p. 19).

22 Nuestra investigación ha identificado un importante grupo de mujeres cabezas de familia, conformando hogares monoparentales ante la separación, muerte o abandono de sus parejas. Las actividades en las que se ubican con mayor facilidad esta el cuidado de niños y ancianos, empleadas domésticas, ayudantes en restaurantes. Mientras los hombres se ubican en la construcción, el comercio. 
miembro de la familia, y, por otro lado, si bien existen decisiones individuales, la aprobación y soporte de la familia es muy importante, en términos económicos y extraeconómicos.

En relación a este punto, cabe destacar, como lo demuestra el estudio de Herrera y Martínez ${ }^{23}$ que no todos los miembros de la familia actúan en igualdad de condiciones y poseen la misma capacidad de acción, existen relaciones de poder, valores culturales e ideológicos que marcan los roles, las identidades de género y las condiciones de reproducción de los individuos. Esto sumado a la activación de las redes familiares y sociales, estaría influyendo en la decisión de migrar, en el destino de la migración y en quien migra. La emigración es también una estrategia familiar de movilidad y de cambio: lo que se busca son nuevas oportunidades y un mejor futuro, que no se vislumbran en Colombia, Cartagena o Barranquilla; la migración es causa y a la vez consecuencia de la construcción de nuevos referentes, que ocasionan como lo describe Walmsley ${ }^{24}$ un "síndrome migratorio" que ha llegado a constituirse, para el caso de hombres y mujeres jóvenes de ciertas comunidades, en una suerte de iniciación a su etapa de madurez.

El sentido del proyecto migratorio esta matizado por los potenciales efectos y beneficios de la familia. Las familias despliegan estrategias tendientes a "gestionar" el complejo proceso de migración activando y movilizando una serie de recursos materiales, simbólicos (inversiones afectivas y organizativas). La toma de decisión y puesta en marcha del proceso migratorio, requiere de una "suerte de pacto previo" entre los miembros de la familia. No debe pensarse, sin embargo que tal pacto supone un consenso amplio y exento de relaciones de poder, conflictos, negociaciones y dominación al interior de la familia -trama que se diferencia y especifica en cada caso, según determinadas relaciones de género-. Por el contrario, tales decisiones están atravesadas por las dinámicas de poder y control social con específicas formas que dependen de la situación del emigrante, si es padre/madre, hombre/mujer, hijo/hija.

Una vez que el pacto se produce comienzan a desarrollarse un conjunto de estrategias colectivas para la obtención de los recursos requeridos para el viaje y simultáneamente para explorar las oportunidades laborales, relaciones y posibilidades de inserción en el país de llegada. Los siguientes testimonios ejemplifican como se establecen esos pactos previos y como comienzan a movilizar los recursos necesarios.

Bueno mi mamá se fue para Venezuela, por Maicao, hace 21 años, pues para esa época era muy fácil entrar a Venezuela y como mi abuela estaba en el pueblo, las dos hermanas de ella estaban allá,

${ }_{23}$ Gioconda Herrera y Alejandra Martínez, Género y Migración en la Región Sur, Quito, FLACSO, 2004.

24 Tim Walsmley, Hijos de Salvadoreñas a New York, San Salvador, Universidad de San Salvador, 2000. 
la llamaron que se fuera para allá, que para que trabajara y ganara más plata. Ella entró sin papeles sin nada, pagaban 20 mil pesos o menos y entraban en esa época no ponían tanto pereque para entrar, entonces ya allá conoció a mí papá, que era del mismo pueblo (Guamal, Magdalena) y allá se quedaron. Hija, Cartagena, 20 años. Ella consultó con nosotros, entonces nosotros teníamos un televisor, ella dijo que se lo prestáramos que cuando ella estuviera allá, ella mandaba la plata del televisor o mandaba otro televisor y lo empeñamos, con esa plata fue que se fue"( Abuela Barranquilla. 46 años).

La situación en Cartagena estaba muy dura era el año 1980, mi mama ya había tenido tres hijos mi papa viajo por adelante, entonces nos dejaron con la abuela materna, ella venia cada año, con el trabajo en Venezuela compramos la casa, le hicimos unas mejoras, y pudimos estudiar, ellos todavía viven allí. Hija Cartagena 22 años.

Los ejemplos anteriores nos muestran una cara de esas "unidades migratorias". 25 Las estrategias y los consiguientes cursos de acción destinados a efectivizar la migración se institucionalizan dentro del marco de propuestas que la familia establece. Los siguientes relatos muestran la migración de padres y madres hasta de cuatro décadas, que vienen alimentando la existencia de estas redes y reproduciendo el imaginario histórico sobre Venezuela a pesar de las fluctuaciones del bolívar y las crisis económicas de este país, continúa siendo un lugar que les ofrece mayores oportunidades y bienestar económico para ellos y sus familias.

Mi papá viajó aproximadamente en el año de 1999 y se radicó en Maracaibo, el motivo por el cual sale es porque la difícil situación de trabajo. El viaja con la ayuda de mi tío paterno, quien migró hace como treinta o cuarenta años, fueron de los primeros familiares que se fueron y le decía bueno, esto acá bajó el bolívar pero al menos hay estabilidad laboral, no te están quitando del puesto de trabajo, los policías no te están persiguiendo, aquí todo lo que tu vendas, cualquier producto se comercializa rápido, el ingreso no es mucho, no vale lo mismo que el peso, pero al menos tienes con que vivir, Después se fue mi mamá, ella también tiene unos familiares allá que se fueron hace mucho tiempo. (Hija 29 años, Cartagena).

"Para que mi papá se fuera a Caracas, contó con el apoyo de un tío que vive allí hace veinte años. No solo le prestó el dinero para el viaje, sino que también le ofreció su casa por espacio de cuatro meses hasta que mi papá se instaló, consiguió trabajo, así la vida se le hizo menos dura". (Hija de 18 años).

25 Utilizamos el concepto de unidades migratorias como una forma de definir a las familias y todo el conjunto de estrategias en relación con el proceso migratorio. Lo tomamos de Alba Goicoechea, Familia, Imaginarios y Redes sociales de la Migración Latinoamericana, Quito, Tesis de grado Maestría en Sociología FLACSO, 2002. 
A mi mamá le ayudo una prima que se había ido para Venezuela hacía muchos años y ya era nacional de allí, la animó, le mandó el dinero y además le consiguió trabajo, todo para que ella se fuera, pues aquí mi mamá estaba muy mal. Mi madre lleva 10 años viviendo en Venezuela, y no piensa regresarse. (Hijo de 16 años).

Las redes familiares también son fundamentales en el país de origen, su apoyo es definitivo en la decisión de migrar, por cuanto el cuidado de los hijos/as que se quedan, es un asunto vital para que se viabilice el proyecto migratorio. En Cartagena y Barranquilla y podría decirse que en la Costa Caribe, la participación de la familia extensa a través de las figuras femeninas de las abuelas y las tías en el cuidado de los hijos ha sido una práctica tradicional ${ }^{26}$ y legitimada en todos los estratos sociales. Algunos de estos testimonios lo confirman:

Siempre tuvimos el apoyo de la familia, ahí estuvieron los tíos y la abuela, cuando mi mamá se va a Venezuela, nosotras, mi hermana y yo, nos quedamos viviendo con ellos". (Hija, Cartagena)

"Mi mamá se va a Venezuela porque tenía familia allá, vivían unos hermanos y unos primas y acá nos quedamos con una tía.( Hija, Cartagena)

"Cuando mi mamá se va a Venezuela, nos quedamos con una tía, y con la abuela. Todos nos quedamos viviendo en la casa de la abuela". Hija, Cartagena)

"Esto de cuidar los nietos no es fácil. Pero de todas maneras fue la forma de colaborarle a mi hija para que se fuera, la separación de la familia duele mucho. La tristeza y la ausencia de ella ha sido dura, pero todo por que pudiera tener un mejor trabajo". (Abuela, Cartagena)

Podría plantearse que vienen siendo las mujeres las que tradicionalmente han estado y están garantizando el cuidado de hijos/as para que muchas madres puedan migrar en busca de oportunidades laborales y mayores ingresos para el sostenimiento de sus hogares; de igual manera cuando migran los padres, es la madre quien queda en el país, brindado protección y cuidado a sus hijos, observando una situación de inequidad de género cuando migran las madres, por cuanto son muy pocos los casos encontrados donde los padres asumen el cuidado y la protección de su prole, delegando esta función en las abuelas, tías o hermanas. Para el caso de Barraquilla, la figura femenina de las primas también aparece con una participación importante dentro de la red familiar. ${ }^{27}$

La niña estaba muy chiquita y mi prima no quería dejarla con otras personas, nos dijo que mejor la dejaba aquí que todo era de

26 Pilar Morad y Gloria Bonilla, "Paternidad y maternidad en Cartagena de Indias. Antes y ahora", en Yolanda Puyana (comp.), Padres y madres en cinco ciudades colombianas, Almudena Editores, 2003.

27 Hallazgos de la investigación en curso en Cartagena, Maicao, Riohacha y Barranquilla. 2009-2010. 
confianza. Ajá y como yo no estaba haciendo nada, yo me quedaba cuidándola... desde ese momento se quedo con nosotras y ya tiene 17 años”. Prima cuidadora Barranquilla.

"Mis dos tíos se fueron para Venezuela hace más de cuarenta años, al morir mi tía en Venezuela, mi tío manda sus dos hijos, y desde ese momento, ellos viven conmigo, porque él decía que él solo, aja no podía con esos dos pelaos" Prima cuidadora Barranquilla.

Los relatos también dan cuenta de los cambios en la situación económica de Venezuela, asociadas a las olas migratorias y a la situación de irregularidad en la cual se encuentran gran parte de padres y madres migrantes, viendo derrumbado el sueño del país próspero, al igual que sus posibilidades de encontrar trabajo y mejores ingresos, a lo cual se suma la devaluación del bolívar con consecuencias cada vez más difíciles para las familias migrantes.

Los relatos reflejan las condiciones laborales y precarias en las que se encuentran algunos migrantes en Venezuela ${ }^{28}$ : bajos salarios, algunos casos sin seguridad social, desempleados y sin posibilidades de enviar remesas a sus familiares.

Mi hija se fue pa Venezuela, me dijo que ella le iba a mandar a sus hijos, pero plata no ha podido mandar porque la plata de allá es diferente a la de acá y esa plata no vale nada, entonces ella le manda que la ropa, mercadito, cosas así , ella les manda pa su alimentación... así cosas, porque plata no pueden, porque como ellos no tiene papeles de allá, ellos allá están trabajando sin papeles" Abuela, Barranquilla (50 años). "hay veces empiezan las peleas, porque ellos no le mandan la plata completa para sus estudios, y ella dice que eso no debe ser así porque ellos saben que siempre que se va a pagar tiene que tener la plata... cuando ella no tiene para los pasajes mis hermanos o mi mamá se los dan". (Tía materna Barranquilla).

Otra situación que está afectando la situación económica de los familiares en estas ciudades, es la dificultad que tienen los migrantes para enviar las remesas desde Venezuela, que obedece a los controles y medidas tomadas por el gobierno de este país para regular el control cambiario, reduciendo en un 50\% las autorizaciones mensuales para las remesas familiares. ${ }^{29} \mathrm{El}$ impacto de esta medida puede observarse a través de algunos relatos:

\footnotetext{
28 Los relatos de entrevistados/as en Cartagena y Barranquilla permiten evidenciar que algunos migrantes no cuentan con un trabajo estable, ni acceso a seguridad social que es mas apremiante cuando están de manera irregular en Venezuela.

29 Noticia publicada por el Agencia AP. Junio, 2009. "Venezuela baja a la mitad remesas para familiares en el exterior" La decisión hace parte del proceso de endurecimiento del control cambiario." La Comisión de Administración de Divisas (Cadivi), redujo de 1800 a 900 dólares las autorizaciones mensuales de divisas que podrán destinarse para las operaciones de remesas a familiares que residen en el exterior. Esta medida se dio a raíz de la caída de los precios del petróleo, principal fuente de ingresos del país". El Tiempo, Bogotá, Junio 5 de 2009.
} 
Ellos a pesar de que están allá, se sienten intranquilos en la parte económica de ver que no alcanzan a cubrir todo... mi hermana y yo que estamos trabajando aportamos, por ejemplo ellos no han mandado giros estos dos meses, no han podido mandar y porque hay una serie de papeleo para poder mandar, entonces nos atrasamos en los pagos". Hija, Cartagena.

"Hay muchas dificultades en el trámite de papeles como están ahora; la tramitología que hay que hacer; hay que hacer una carta apostillada y una cantidad de cosas que les están pidiendo para poder enviar dinero. Actualmente en Colombia hay una cantidad de gente que no lo está recibiendo por la cantidad de requisitos que les piden. Hijo, Barranquilla.

El anterior análisis nos provoca diversos interrogantes: La migración a Venezuela continua siendo atractiva para padres y madres de nuestra región? O es el contexto económico, político y social de nuestras ciudades caribeñas las que siguen provocando una migración no voluntaria ante las pocas oportunidades que aquí encuentran sus nativos en los sectores de más bajos ingresos para resolver sus necesidades básicas o ejercer sus derechos?

\section{Consideraciones finales}

Podríamos concluir que la continuidad en la tradición migratoria de familias de la Costa Caribe hacia Venezuela ha estado soportada históricamente en las redes familiares y sociales, las cuales han brindado apoyo intergeneracionalmente durante todo el proceso migratorio, que se continúan potencializando entre los dos países, dada la proximidad territorial, los costos de transporte, el acceso y tráfico irregular transfronterizo.

El soporte de las redes familiares es un factor que reproduce el imaginario de prosperidad y oportunidades de los migrantes en Venezuela y se expresa en diversas acciones desde los dos países: ayuda económica en caso de que el padre o la madre no obtenga empleo rápidamente, vivienda, gestión de los papeles y permisos, y el cuidado de los hijos o hijas que quedan en el país.

La migración de Cartagena y Barranquilla hacia Venezuela, se caracteriza por ser una migración de supervivencia de familias de bajas condiciones económicas, que no logran satisfacer sus necesidades básicas, y que consideran que allá podrán encontrar las oportunidades que aquí no han sido posibles, pero que no necesariamente ha contribuido, ni está contribuyendo a la superación de su situación de pobreza en ninguno de los dos países.

La migración de padres y madres hacia Venezuela esta soportada además, por la participación activa de las mujeres que desde la solidaridad, y relaciones 
de confianza, asumen el cuidado de los hijos/as que se quedan, brindando protección y cuidado, como una forma de contrarrestar el vivir entre dos países, y ejercer una paternidad y/o maternidad a través de la distancia y en medio de conflictos y tensiones.

La convergencia de estrategias colectivas e individuales y la constitución de redes sociales consolidan, dan forma y explican el circuito migratorio, pero además producen efectos de aislar y/o modular los elementos estructurales vinculados con la crisis histórica y actual del país y de nuestra región. La elección del país de destino por parte de padres y madres está relacionada con los imaginarios construidos sobre la prosperidad, el desarrollo económico los sistemas políticos y sociales que podrían garantizar oportunidades más justas y equitativas frente a la protección del trabajo y la integridad de sus habitantes, que se promueven a través de los medios de comunicación, pero además por las cadenas migratorias existentes entre Colombia y los países de llegada hacia los cuales están migrando las familias.

A partir de las entrevistas realizadas en las ciudades de Cartagena y Barraquilla, Riohacha y Maicao, se han identificado flujos migratorios que muestran posibles tendencias en los países de destino. En el Caribe Colombiano hay un predominio hacia Venezuela especialmente en los estratos 1 y 2, en contraste en los estratos más altos e concentra la población hacia EE.U.U y España, y en menor frecuencia hacia Panamá, Curazao e Italia.

Al mirar de forma retrospectiva el fenómeno migratorio de colombianos o colombianas hacia estos países se encuentra que las cadenas migratorias hacia los Estados Unidos, coinciden con la migración hacia Venezuela, en los años setenta y comienzos de los ochenta, pero esta a diferencia de la migración hacia el país fronterizo, tiene un incremento significativo en los noventa, tal como se registra también para España.

La migración colombiana hacía Venezuela entre los años 70 y 76, estuvo muy asociada a su dinámica económica, pues el sector agroindustrial y la creciente industria petrolera produjeron una constante demanda de mano de obra de baja cualificación en el país vecino, por lo cual el Estado venezolano se ve obligado a regular esta migración. ${ }^{30}$ Unido a lo anterior, la crisis energética en este periodo hace de los países productores de petróleo como Venezuela, escenario propicio para emprender un camino hacía el desarrollo económico y social. Por tanto, en los 70 y mediados de los 80 se da un crecimiento acelerado de la comunidad migrante, sobre todo colombianos o colombianas por la porosidad de la frontera,

30 Estatuto de seguridad fronterizo que aunque había sido creado en el 1942 y ratificado en el 1944 sólo hasta el 72-76 se le comienza a dar aplicabilidad. Juan Carlos Tanus, "Migración de Colombianos a Venezuela". Entrevista en La agenda del sur. Tema del día. La odisea de los migrantes latinoamericanos En: http://www.solociencia.com/videos/online/Migracion\%20humana/. Consultada el 22 de diciembre de 2009. 
y por las amplias oportunidades laborales y económicas para todo aquel que fuera a emigra. ${ }^{31}$

Dadas estas condiciones que ofrecía Venezuela, Cartagena de Indias, Barranquilla, Riohacha, Maicao, Magangue por ser ciudades cercanas al país, no estarían al margen de este fenómeno. La dinámica de estos flujos migratorios a Venezuela se fue intensificando con la información que llegaba a los y las migrantes potenciales a través de familiares y/o amigos/as sobre las condiciones de vida y las oportunidades laborales en las regiones de destino. Así las familias de Cartagena y Barranquilla se constituyen en iniciadoras de las cadenas migratorias estimulando y facilitando el acceso al trabajo, y promoviendo en la mayoría de los casos una serie de estrategias de sobre vivencia y asistencia dentro del proyecto migratorio.

Para fines de la década de 1970 con la llamada "segunda onda expansiva" de migración internacional hacia Venezuela lo que distinguió el proceso de inmigración --sobre todo luego de 1973-- no fue tanto el nivel cuantitativo, si bien este fue significativo, sino la redefinición de la política oficial en cuanto al lugar del inmigrante como factor de producción. En este contexto, la inmigración fue vista por el gobierno y diversos sectores privados de la industria y la agricultura como importación de mano de obra. El crecimiento de la producción agrícola y la alta tasa de urbanización crearon las condiciones durante esta década para una escasez de mano de obra sobre todo en el sector de la agricultura y, por consiguiente, surgió la necesidad de absorción de trabajadores extranjeros en condiciones legales o no.

31 Marco Marenco y Robles, Nelcy., Venezuela: flujo migratorio, reflujo monetario. Trabajo de grado para optar por el titulo de Economistas. Universidad del Atlántico, Facultad de Ciencias Económicas. Barranquilla. 1981 


\section{Bibliografía}

Agrela Belén, "Ser Madres en familias trasnacionales", en $V$ Congreso Migraciones, Asociación de Emigrantes, Bilbao, 2002

Alba Goicoechea y Franklin Ramírez, Los hijos de la Migración. Impactos sociales en la familia, Quito, Universidad Simón Bolívar, 2008

Alba Goicoechea, Familia, Imaginarios y Redes sociales de la Migración Latinoamericana, Quito, Tesis de grado Maestría en Sociología FLACSO, 2002.

Alcides Gómez y Julio Mora, Flujos migratorios de las zonas de frontera colombiana a Venezuela, Caracas, Universidad de Maracaibo/Universidad Central de Venezuela/Centro de Investigaciones Demográficas, 1972.

Alcides Gómez, Dinámica de las migraciones colombianas a Venezuela, Bogota, Universidad Nacional/ Tercer Mundo, 1999.

Ana Luz Borrero, “Migración Latinoamericana a España”, en Revista Migraciones, Barcelona, 2001.

Ana Maria Bidegain, y Antonio Frietz. Colombianos a Venezuela: mito y realidad. Caracas, Centro de Estudios de la Pastoral Social y Asistencia Migratoria. 1989

, Las migraciones laborales de colombianos a Venezuela. Caracas, Instituto Latinoamericano de Investigaciones Sociales, 1987.

Chen, Chi Y, Inserción laboral y migración colombiana a Venezuela, Caracas, Instituto de Investigaciones Sociales y Económicas, 1989

Documento CEPAL-CELADE-OIM. Proyecto SIMICA. Por otra parte, a nivel interno las regiones de mayor flujo migratorio hacia este país han sido la región oriental y la Costa Atlántica de Colombia.

Douglas, Massey, Arango, et.al. Teorías sobre migración internacional. Una reseña y aproximación. En: Population and Development Review, 19, No. 3. Septiembre. Traducido del inglés por Augusto Aguilar Calahorro. Publicado en: ReDCE, No. 10-Diciembre, 2008. Joaquín, Arango, (2000) Enfoques conceptuales y teóricos para explicar la migración” en Revista Internacional de Ciencias Sociales No. 165. UNESCO.

Encuesta Nacional 2008-2009. Resultados generales de Migraciones Internacionales y Remesas. Observatorio Distrital de Migraciones. Bogotá D.C. Observatorio Colombiano de Migraciones. Fundación Esperanza-Red Alma Mater. P. 33. 2009.

Gabriel Murillo, La emigración laboral de colombianos a Venezuela, Bogota, PNUD, Ministerio de Trabajo, 1979.

German Freire, "Migraciones rurales. Un estudio a ambos lados de la frontera Colombovenezolana”, en Boletín Antropológico Mérida, Universidad de los Andes, 2004

Gioconda Herrera y Alejandra Martínez, Género y Migración en la Región Sur, Quito, FLACSO, 2004.

Isabel Yepes y Gioconda Herrera, Nuevas Migraciones Latinoamericanas a Europa. Balances y Desafíos, Quito, FLACSO, 2009

Jason Pribilsky, "Los hijos de las remesas, y traumas de la globalización", en Ecuador Debate No. 54, Quito, 2000. 
Luis Llambi, "The Venezuela-Colombia Borderlands: a regional and historical perspectiva". En Jornal of Borderlands Studies, IV, (1): 1-38. 1989.

Luz Marina Díaz y Alcides Gómez, "Fuerza de trabajo y mercado laboral de los migrantes colombianos a Venezuela", en Las migraciones de colombianos a Venezuela, UCAB, Caracas, 1987.

Oveja Negra, 1983.

La Moderna esclavitud los indocumentados colombianos a Venezuela, Bogota, Editorial

Pablo Villafañe, Migración a de colombianos al Táchira 1903-1983, San Cristóbal, Biblioteca de Autores Tachirenses, 1983.

Pilar Morad y Gloria Bonilla, "Paternidad y maternidad en Cartagena de Indias. Antes y ahora", en Yolanda Puyana (comp.), Padres y madres en cinco ciudades colombianas, Almudena Editores, 2003.

Raquel Álvarez, "Evolución histórica de las migraciones a Venezuela. Breve recuento", en Aldea Mundo, San Cristóbal Venezuela, Universidad de los Andes, 2006.

, "La dinámica migratoria colombo-venezolana: Evolución y perspectiva actual", en Geoenseñanza vol 9, No. 2, Mérida, Universidad de los Andes, 2004

„, Evolución Histórica de Emigrantes a Venezuela. Ministerio de Relaciones Exteriores de Venezuela, Caracas, 2007.

Ricardo Dávila, "Fronteras Confusas. Impactos sociales de la migración" En Revista Virtual de Estudios Literarios y Culturales Centroamericanos, Itsmo. Universidad de los Andes, Venezuela, 2002, disponible en: collaborations. denison.edu/istmo/.../fronteras.html.consultada en diciembre, 2009.

, "Migración indocumentada a Venezuela", Memorias Congreso Migraciones, Trabajo y Crisis Económica en América Latina, Universidad de Costa Rica, 2000.

Ricardo Torralba, Las migraciones de colombianos a Venezuela. Universidad de los Andes, Caracas, 1987.

Susan Berglund y Humberto Hernández, Los de afuera: Un estudio analítico del proceso migratorio a Venezuela 1936-1985, Caracas, CEPAM, 1986

$\mathrm{T}$

im Walsmley, Hijos de Salvadoreñas a New York, San Salvador, Universidad de San Salvador, 2000.

Wagner Keike, "Migrantes Ecuatorianos en Madrid. Reconstruyendo Identidades de Genero", en. Ecuador Debate No. 63, Quito, 2004. 